The most impressive records of this conference are the attainment of a resolution of $20 \mathrm{~A}$. for normal working of certain microscopes, and of $10 \mathrm{~A}$. under especially favourable conditions; quite astonishing improvement in microtomy of embedded biological material, enabling specialists in this work to produce, as a matter of routine, sections of thickness of the order of $200 \mathrm{~A}$. ; and a most useful extension and general improvement of the replica technique.

The immediate effect of all this on research in many fields is well illustrated in the eighty-one communications relating to applications. Detail of molecular dimensions was observed in many biological specimens, including cell walls (for example, of a species of Spirillum) ; lamellæ of nerve myelin sheaths ; and organic crystals, for example, ferritin, in which a section of the lattice was clearly visible. Virus particles were photographed at the site of interaction with the host cell (for example, Herpes simplex on chorioallantoic membrane); and particles of poliomyelitis virus of the Lansing strain, from the central nervous system, were identified and photographed. Cilia from ciliated epithelia, from Lamellibranchia, Amphibia and Mammalia, were found to contain eleven fibrils, always in the same arrangement of two inner and nine outer. Collagen was a popular object of study, and the interesting phenomenon of the reconstitution of this material from solution received special attention. Good use was made of tissue culture, particularly for the production of specimens for electron microscopy in biophysical research.

Emission and ion microscopy gave improved resolution, which showed, for the first time, an orderly array of atoms of the emitting point. More orthodox metallography was represented by contributions showing steady, though less spectacular, progress, in some of which good use was made of a combination of microscopy and electron diffraction.

Much of the apparatus and many of the techniques described in this publication represent such an advanced stage of development as to render this account of them of considerable permanent value to all interested in the stady of fine structure. The book is well produced, with excellent illustrations, and is likely to remain for some years the best compendium of information on non-optical microscopy.

H. I. Matthews

\section{THE TEETH OF AUSTRALOPITHECUS}

\section{The Dentition of the Australopithecinae}

By J. T. Robinson. (Transvaal Museum Memoir, No. 9.) Pp. vi +180 . (Pretoria: 'Transvaal Museum, 1956.) n.p.

THERE is a certain inevitability in the trend of 1 the discussions which follow the discovery of fossil relics of early man and his precursors, an inevitability which seems to stem from the fact that in their early stage the discussions so often take place between those who have made an intimate study of the fossil material itself but do not have at hand adequate material for detailed comparisons, and those who may have ready access to comparative material but have not studied (and perhaps have never even seen) the original fossil specimens. It is little wonder, then, that conflicts of opinion easily arise, and rather profitless controversies ensue.
Fortunately it is also inevitable that, sooner or later, the significance of the discovery is put into perspective by much more detailed and comprehensive studies. In the case of the Australopithecinae of South Africa- those early Pleistocene creatures so ape-like in the general proportion of the brain-case and jaws and yet approximating so closely to man in a number of morphological characters of the skull, teeth and post-cranial skeleton-the need for such studies has for some time been evident enough. The publication of a monograph on the dentition is for this reason alone particularly welcome, but it is also of unusual importance because of the accepted reliability of comparative odontology for the assessment of taxonomic relationships. The author, Dr. J. T. Robinson, of the Transvaal Museum, Pretoria, is well qualified to carry out this work, for he has himself been responsible for excavating much of the fossil material, and also, by extended visits to museum collections in Europe and America, he has acquired a very considerable experience of the comparative odontology of apes, both recent and extinct.

This monograph is essentially a systematic and sober descriptive account of the australopithecine dentition based on the study of more than five hundred teeth. Many of the latter are perfectly preserved and still in position in upper and lower jaws, and they include numerous examples of the deciduous as well as the permanent dentition. The text is illustrated by almost two hundred photographs and drawings which are unusually excellent in their clarity. The author is not concerned to raise controversial issues; he gives a dispassionate appraisal of the dental evidence for determining the taxonomic position of the Australopithecinae; but, in the main, he is content to allow the evidence to speak for itself. He points out that in the shape, relative size and nature of wear of the canine teeth, the consistent absence of a diastema, the bicuspid character of the first lower premolar, the multicuspid character of the first deciduous molar, and the shape of the dental arcade, the dentition conforms to the hominid rather than the pongid pattern, and he concludes, therefore, that as between the Pongidae and the Hominidae the Australopithecinae are to be assigned (at any rate on the evidence of the dentition) to the latter. He also notes that this conclusion is in conformity with the evidence of other parts of the skeleton, and particularly the pelvis (of which there have now been discovered four specimens). Dr. Robinson permits himself only a brief discussion at the end of his monograph on the significance of the South African fossils for hominid phylogeny, and while he makes it clear that they are hominids in the taxonomic sense, he regards it as unlikely that the groups whose remains have so far been found bear a direct ancestral relationship to Homo. Certain speculations are also advanced regarding the affinitios of the Hominidae and the Pongidae. Not all these are likely to find general acceptance; indeed, the present writer would be prepared to question the logicality of some of the arguments presented. But they are, of course, no more than provisional interpretations, and they no doubt require serious consideration. It is to be hoped that this monograph heralds the appearance of a series of similar studies by the same author, for such a sequence of contributions would be of outstanding importance for what is, after all, the main problem of palæo-anthropology, the phylogenetic relationships of man.

W. E. Le Gros Clark 